plan aloo adopted by Mr. Brichsen) is al ways a useful hand, which cannot be said for the hand with the phalanx as an obstruction.*

K.

\section{Oringinal Communirations.}

\section{CASE OF IDIOPATHIC TETANUS.}

By Thomas L. Pridham, Esq., Bideford, Devon.

Constantins Bowman, aged 27 years, the subject of the following interesting case of tetanus, had suffered from a low epidemic fever, which had prevailed in this district about six weeks prior to his present attack, during which he had considerable hremorrhage from his bowels. He recovered slowly, and on the 19th of the present month he went to his work in tolerable condition; but he was weak, and not able to do much. During the day he drank two half-pints of Stogumber beer.

Early on the morning of the 20th, I was requested to visit him. Having inquired of the person who came for me, who appeared an intelligent man, somewhat of his state, I forwarded by him a draught containing thirty drops of tincture of henbane in camphor mixture. I visited him two hours afterwards, which was at six o'clock. I found, after taking the draught I had sent, that he had slept; and, at the time I saw him, he was perfectly quiet and reasonable, complaining only of a serere pain in the back of his head. He told me he had gone to bed apparently perfectly well, having eaten a meat supper, with bread, but no kind of stimulus was taken; that he awoke between three and four o'clock, with a sensation of shaking of his limbs, which he could not control, and a pain at the back of the head and a little down the spine. He said his feelings and ideas soon became uncontrollable, and he felt a great desire to destroy himself, his wife, and child. His breathing was oppressed. He told me he had repeatedly struck his head against the bed, and once against the wall, in which there was an evident mark; for so violent had he been that the laths and plaster had been driven in correspondingly with the size of his head. His great desire was to strike his head where he suffered the most pain, saying that he should then be well. He further remarked, that his head became drawn back, his heels drawn up, his jaw fixed, and his hands clenched. His account of himself and what had passed was confirmed by his wife and those persons whom she had called to her assistance. The attack lasted one hour. When I saw him, his pulse was 76 , soft, and free; tongue moist and slightly coated. The pain in the region of the occiput still continued. I ordered an active aperient, and left him.

Two hours afterwards, I was again summoned to visit him. The messenger informed me that Bowman had been again seized as in the early morning. At the time I visited him, he was in a tetanic state; head drawn back; heels drawn backwards and upwards; jaw fixed; hands clenched; respiration slow; pulse 96 ; eyes with a strange and wild expression, pupils much dilated; intense pain under the occiput and down the neck; heat about the head. The bowels had been acted on freely. Mustard poultices were ordered to the spine, soles of the feet, and calves of the legs; tha hair to be removed, and cold to be applied to the head, and a large blister to the back of the neck. I learnt that, before the tetanic spasms had come on, he had been restrained, as the efforts to commit violence on himself and others had been very great. This attack lasted about two hours, and it left the patient quite exhausted and weak, with a sensation of numbness of the lower extremities. As soon as he was able to swallow, I gave him sixty drops of tincture of henbane in camphor mixture, and further

- A most interesting operation of this kind was also performed by Mr. Marshall at University College Hospital, on May 28th, iu a case in which excessive hemorrhagic diathesis existed. The finger was removed by the gulvanic cantory. prescribed three grains of calomel with ten drops of liquor opii sedativus, to be taken every three hours.

Another attack of equal severity came on twelve hours. Another attack of equal sererill continued. The blister was ordered to be dressed with mercurial ointment.

The fourth attack came on at the end of another twelre hours. It was not, howerer, quite so severe as the former ones; but still the same stages of the disease, with the deones; but still the same stages of the disease, with the commit violence, were present. During the intervals of the attack, he spoke of his feelings prior to, at the time of, and subsequent to, the attack. He said that, when the spasms were on him, he was exceedingly impatient of rethe spasms were he had the desire to commit violence; that his breathing was oppressed during his tetanic state. His attendants remarked that they knew when the attack was coming, by marked that they knew when the attack was co that some one would hold his hands, to prevent his striking either the parson (who was present) or the doctor.

I watched the case closely for twenty-four hours longer, during which time he was attacked twice; but the attacks gradually diminished in severity; and as his gums became sore so in proportion did the disease appear to subside. He took in the whole about sixty grains of calomel. Indications of the disease, however, made their appearance at the intervals of each returning period of twelve hours for two days. He is now, on the 30 th of the month, rapidly recovering; appetite good; tongue clean; pulse 70 , soft and free. He sleeps well, and expresses himself grateful for having been relieved from so frightful an attack, during which, he says, he nerer lost his sense of consciousness, and recollects everything that has passed.

REMarks. The events which have been passing during the last fortnight in the Central Criminal Court in London induce me to send this case for publication in the Associa tion JoukNAI, as it will certainly add to those cases already published of idiopathic tetanus which closely resemble those of the traumatic form. It forcibly reminds me of two cases of traumatic tetanus which I have seen in private practice, caused by injury inflicted on the body by accidents; nor can it be denied that it resembles in many particulars those cases of tetanus which have of late been described as occurring after taking the deadly poison of strychnia into the stomach. In Bowman's case there is not the slightest suspicion of poison being taken, or of injury sustained. The uncontrollable desire to destroy life on the approach of an attack is remarkable, and interesting to those who regard phrenology as a science.

In conclusion, I have to remark that Bowman is of a peculiarly anxious and nervous temperament. He was, moreover, somewhat in difficulties, in consequence of his long illness; and this circumstance appeared to press heavily upon his mind; and it is more than probable that the small amount of stimulus which he had taken in his labour acted on an irritable and excited brain, producing congestion, and it may be, to a certain extent, inflammation about its the base: and hence the train of symptoms which I have described, which evidently yielded to the prescribed treatment. My medical friend, Mr. Thompson, saw the case with me.

\section{NOTES ON THE PATHOLOGY AND TREATMENT OF ULCERS OF THE LEG.}

By JoHN KENT SPENDER, Esq., Surgeon to the Eastern Dispensary, Bath.

$$
\text { [Concluded from page 364.] }
$$

Gengral principles of treatment, like all other rules, admit of some exceptions, and require some modifications in practice. The instances in which the plan of chalky incrustation and compression has answered most completely are superficial ulcerations, however extensive the surface may be, and whether dependent on varix or not. There is less destruction of parts, and consequently less demand upon the reparatory processes. Then it will generally be 
found that doep and callous nlcers require a opecial treatment $\rightarrow$ condition which is fulfilled by the addition of a stimulant (the nitric oxide of mercury is the best) to the axdinary chalk oirtment. But in those cases in which this mothod altogether fails to produce a cure, or in which it is tandy and uncertain, the strapping must be resorted to ; its utility being admitted by the concurrent testimony of almost every modern writer. The resin acts as a beneficial stimulus, while pressure can be commanded to any degree by using the roller throughout the whole extent of the limb.

In particular cases of superficial ulceration, in which irritability is the principal characteristic, we may suspect the existence of some form of toxæmia. This opinion will be confirmed if we find the disease non-amenable to the ordinary chemical and mechanical remedies; plainly declaring that some morbific principle is at work, which derelopes itself at certain spots determinable by previous local injury or possible impairment of nutrition.

Knowledge of the specitic properties of anv article in the Materia Medica, or of any compound in the Pharmacopoia, confers upon us a power which is equivalent to an enhanced skill in diagnosis. Such knowledge may have been originally gained entirely by accident, so that the use of an agent under any given circumstances becomes strictly empirical, because it is not based upon any known phenomena connected with its physiological action. But our experience of its therapeutical history is not the less precise and sure; since this experience is built upon the results obtained by simple observation and trial. And in practice it will be found that ignorance of the curative properties of a medicine is occasionally more disadvantageous than absolute error in the discrimination of disease. Bring before me a case which bears the image and superscription of chronic suffering, and which tells its own tale of past woe: here, perhaps, is an unmistakeable specific disease begging for its own specific remedy; but if I do not know that remedy, or how to apply it, my patient must linger on with his pains unrelieved, and my own remedial skill undeclared. Another medical man achieves a perfect cure in a few weeks; and immediately every tribute is paid to his supposed superior diagnostic ability, though his success is entirely due to a lucky discovery, or to a more extended acquaintance with the past and the current literature of therapeutics.

These observations apply with especial force to two particular agents-iodine and tar. A specimen of dermal disease which defies all other remedies may be submitted to the influence of either of these, with a fair probability of success. The most elementary process of reasoning invites us to try extraordinary means for the control of extraordinary morbid states; and, upon the mere doctrine of chances, good is at least as likely to result as evil. And it is really astonishing how much credit may be sometimes gained in this cheap and facile way; and we can hardly be persuaded to rob ourselves of this credit when we see a patient almost literally take up his bed and walk, and apply a once damaged and useless limb to the purposes for which Nature degigned it.

Experimental combinations of the ointments of tar and chalk, and of those of iodine and chalk, are found to subdue many forms of irritable ulceration in the lower extremity which have altogether defied routine measures. Dr. Hughes Bennett and others confirm the immense utility of the external application of tar in all dermal affections of - psoriasical character; and the moist spongy ulceration which sometimes attacks the leg seems to possess a pathological affinity with psoriasis, as it is generally controllable by identical mcans. The mineral constituent of the ointment fulfils the mechanical condition of furnishing the incrustation, while the tar affords that specific element in the treatment which is required to meet the specific element in the disease. But the use of the bandage is of equal importance, as it affords support to the veins, approximates the dilated cells of the areolar tissue, and promotes the absorption of serum.
I have a caee nor noder my care phich illustrates the properties of the external use of iodine. Three ulcers, with indurated edges, were situated just below the knee: they had resisted every kind of treatment before the patient applied to me; and I found that they also baffled my own ordinary methods. Careful inquiry elicited a remote history of syphilis. Acting upon this knowledge, I added a small proportion of compound iodine ointment to the ordinary chalk and mercurial ointment; and this, combined with firm pressure, produced a rapid and satisfactory cure.

The judicious use of constitutional remedies is of signal importance in all these cases. The secretions from the intestinal, renal, and cutaneous tracts of membrane, require to be encouraged and maintained; while appropriate hygienic measures contribute to the general good effect. Then it is very likely that the administration of the alkalies, or of iodide of potassium, or of small doses of opium, may seem to be called for by the special exigencies of the local disease, or of particular systemic derangements.

I have now described a method of treating ulcerated legs which has been followed with very great success. It is a method which was suggested by theory, but it is confirmed by constant practice; it imitates and assists the natural prccess, and accomplishes a cure usually in a certain and speedy manner. If it be philosophically right, then other opposite methods must be as surely philosophically wrong; and I believe that the infallible criterion of practice generally proves them to be so.

First, let me allude to that ubiquitous remedy, the poultice. This may be truly called the refuge of ignorance and of neglect. It is often prescribed without discrimination, and continued for the bad reason that we know not what better to do. For consider what a poultice is. It is a vehicle of heat and moisture-a combination of physical agencies calculated to dilate and to weaken the structures to which it is applied. It is exactly the contrary to a tonic, whether of a mechanical or of a vital kind ; and therefore it is at utter variance with those principles which I have endeavoured to prove to be the foundation of the rational treatment of varicose ulcers of the legs. Incompleted sloughing is the only case in which an apology can be offered for the use of poultices; and even here I believe that a quicker result would be often attained by the bold and early use of compression. Under any other circumstances, a poultice can do scarcely anything but harm, and cannot be condemned in too emphatic terms. The character of an ulcer is materially deteriorated; healthy granulations become soft and bloodless; and the edges of the sore are rendered pale and unorganisable. Then the protective layer of purulent secretion is absorbed and taken away, and consequently the reparatory process is proportionately retarded. In few and decisive words, the application of a poultice is nothing less than a mischievous interference with the natural healing operations.

Lotious of every kind are quite as prejudicial. The constant application of cold water, however useful the substance may be of which it is the vehicle, is exceedingly injurious to a limb the temperature of which is already reduced by the obstructions in the capillary and venous circulations. Those progressive metamorphic actions in an ulcer which indicate that sound cicatrisation is being carried on, are arrested by the devitalising effects of cold, and a retrograde step takes place which sometimes approaches the condition of gangrenie. It is frequently $\mathrm{mJ}$ lot to see cases exemplifying this fact; and it is almost equally often my lot to see them improve under the influence of the local stimuli of warmth and pressure.

When we are led to believe the uselessness of poultices and lotions by a study of principles, and are thoroughly convinced of it by observation in practice, we shall begin to reflect why we are wrong, and how we may become right. The surest plan for making any disease an opprobrium in medicine or in surgery is to forget or to ignore its cause, and consequently to err in the management and control of its obvious effect. Constant failure should lead us to suspect whether we may not have lost the clue to the correc- 
tion of an abnormal stato; and it is certain that wo take more interest in any department of our art in which we have the steady light of a definite principle to guide us. Is it not so? Do not good intentions lose their practical force if not animated by sound knowledge? Complete discouragement gradually succeeds, and we alternately blame nature and blame ourselres.*

To keep patients in bed is also an usual element in the prescription for the treatment of varicose ulcers of the leg. Here we see another offshoot of error, originating with the supposition that the disease owes its origin to a physiological, and not to a pathological, state. Compression answers every object to be gained by the assumption of the recumbent posture; and the help which this may theoretically be supposed to afford by no means counterbalances the acknowledged evils dependent upon the loss of constitutional exercise. Then we ought to recollect that it is with many individuals a matter of most serious inconvenience to be compelled to abandon their pursuits and lie in bed. Their arocations are of such a nature, and of so much importance to their very subsistence, that they cannot afford to be idle. And this is also a matter of some moment in the economy of a hospital, where we frequently find beds occupied by cases of ulcer for an indefinite length of time, to the exclusion of other more urgent and more interesting forms of disease.

Exercise of the extremity without the use of pressure, must, of course, do harm; but whenever compression is resorted to, exercise confers the direct and positive benefit of assisting and sustaining those processes which are necessary for accomplishing the act of restoration. It bas been well observed, that "rest of the limb admits of the healing of the ulcer by a degree of action which is unable to keep the part sound, and prevents this degree of action from being increased by the stimulus which exercise affords. But exercise sets up an additional energy in the process of reparation, both directly by the effects of it as a stimulus, and indirectly by the very obstacle which it places before the healing function : for all living actions are strengthened by the opposition they have to encounter." It is in consequence of the healthy stimulus which exercise affords to the granulations, and the check which it imparts to their growth, that explains one of the reasons why ulcers get well so quickly and permanently while individuals are walking about. I have numerous facts in $\mathrm{my}$ possession which have practically determined this question, and authorise us to regard moderate use of the limb (with the single exceptional case in which active inflammation exists) as one of the rational elements of our treatment. $t$

The effects of a pathological state may sometimes be anticipated by employing compression on many legs in which an ulcer has not yet appeared. If our science is so often at fault in the attempt to remore an evil, we ought to discover in this the stronger inducement to ward off its approach. The principle is alike in both cases. Whenever a limb is manifestly varicose and enlarged, even though the integument be perfectly intact, we at once note the signal of coming danger, and apply our remedies accordingly. Equal vigilance is necessary that during the treatment of an actual ulcer, the compression is not too suddenly discontinued, or diminished in force at too early a stage.

An appropriate conclusion to this series of papers may consist in the enumeration of, and brief comment upon, the various measures which have been proposed for the treatment of the varicose ulcer of the leg.

These measures may be comprised under two classesthe medical and the surgical.

Of the latter, I shall first notice Mr. Syme's proposal for blistering the edges of the callous ulcer. The effects of the blister are principally dynamical, and are said to disperse the subcutaneous induration and thickening, and so

- Let it be repeated, that my observations on poultices and lotions apply only to the treatment of raricose uicers.

t may hero remart that Dr. Underwood and Mr. Chapman fully recogniced the ralue of exercise as a curative stimulus. to remore the obstacle opposed to healing action." The obrious objection to this method is, that it establishes another solution of integumental continuity in addition to that already in existence, and may therefore materially eme cause of the original lesion remains untouched, and it would theoretically appear undesirable to attempt to remedy one evil by creating another.

Mr. Holt has proposed the exclusion of atmospheric air as an agent in the treatment of ulcers of the lower extremity. $t$ From a piece of adhesive plaster, somewhat larger than the sore, a portion, just the size of the latter, is cut out; the plaster is then applied to the part, and painted with collodion. Oiled silk is now placed over the ulcer, and made to adhere to the plaster by means of the collodion, by which process the air is completely excluded from the ulcerated surface. The whole is then secured by strips of adhesive plaster placed crosswise, and by a roller running from the toes to above the knee. Two cases are recorded in which perfect cicatrisation was effected. I imagine that the benefit resulted almost solely from the judicious use of compression rather than from any specific good derivable from the exclusion of atmospheric air.

$M$. Denonvilliers has recently brought glycerine under the notice of the Paris Société de Chirurgie, speaking highly of it as a very clean application for ulcers. $t$ Glycorine has been compared with the oils, and has been supposed to act as an inert substance, protecting wounds as neutral fatty bodies do. It is, however, a body analogous to alcohol; and so far from being inert in its action on the organic tissues, it penetrates these more rapidly than water does, and exerts a special action on several of them.

The application of charcoal to ulcers of the leg has found an advocate in Dr. Neumann. S Strips of adhesive plaster are applied above and below the sore, and across its middle, the intervals between the strips being strewed with charcoal corered with ointment, spread on lint, and bandaged; this dressing is renewed every two or three days. In this manner ulcers, which have continued open for years, have been healed in six or eight weeks, the patient still taking moderate exercise. Complete exclusion of atmospheric air is the principle aimed at by Dr. Neumann's plan.

Mr. Gay maintains that the obstacles to the entire and permanent healing of indolent ulcers are to be found directly in the condition either of their edges or of the adjoining tissues, or in that of both conjointly. In other words, the edge of the ulcer is not free to contract, or the adjoining textures are not free to yield to the traction that the edge, in closing in, makes upon them.| Mr. Gay has, therefore, suggested that an incision be made through the healthy skin and superficial fascia, within a short distance of the edge of the ulcer, in a direction parallel to the axis of the limb, and, therefore, at right angles with the line of principal tension. I have never yet tried this operation, simply because I have never yet met with a patient who would submit to it. However sound in principle it may appear, yet there is the obvious risk that the artificial openings may become as reluctant to heal as the original lesion. Mr. Chapman has since commented upon Mr. Gay's proposal, and adopts a modification of it which he considers simpler in performance, and attended with less danger; but he admits that the cases are extremely few in which an operation is indispensable; and still fewer, he thinks, are the private patients who will allow the treatment of an ulcer on the leg by the scalpel, even when all other atcempts have failed. T

To Mr. Hainworth is due the credit of criticising and reviving the ancient practice of excising the margin of the callous ulcer.** The primary obstacle to successful treat-

* Contributions to Pathology and Practice of Surgery, quoted in "Med. Gazecte", Feb. 25th, 184X.

+ Lancet, April 24th, 1×52. $\ddagger$ Gaz. des Hópitaux,

Mod. Rov.", April 1856.

I Brit. and Hor. Med. Rev., April 1850

I, Iancet, June $18 \mathrm{th}, 1853$.

Medical Times and Gazette, August 13th, 1853

- Labcet, January 21st, 1834. 
ment in this case is the presence of a solid ring of compact and indurated effete cuticle, which constricts the vessels of the cutis immediately around the ulcer, and consequently arrests the formation of ner skin. Several methods of treatment have been directed to the exclusive object of remoring this ring, as a necessary introduction to other treatment; but Mr. Hainworth believes that the most safe, casy, and expeditious method is to perform its entire excision. The operation appears to date its origin at least as far back as the days of Hippocrates; and in the Sydenham Society's edition of the works of that author, and of Paulus Agineta, Dr. Adams has shown that it was advised and practised by them, and by a long succession of great authorities, down to a comparatively recent period. In the non-varicose form of indolent ulcer, there can be no doubt of the signal value of the method here proposed.

The application of the electric moxa has been explained and illustrated by the late Dr. Golding Bird and by Mr. Spencer Wells. My experience of this remedy is rery limited, but it has appeared to be a remedy of great efficacy in the indolent form of traumatic ulcer.

The internal administration of several specific remedies has been recommended-some apparently on empirical grounds-as the tincture of cantharides and the oil of turpentine; but the use of opium is advocated by Mr. Skey upon principles which are unquestionably authentic and sound.

A description of the palliative and radical treatment of varicose veins is not within the limits of my subject. I may, however, refer to a capital resume of this question in the Gazette des H6pitaux for Jan. 17, 1854, in which M. Nélaton criticises the various modes which have been adopted, and admits that he confines himself to a palliative treatment by uniform pressure of the varicose limb by an elastic bandage.

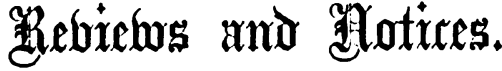

Memorr on the Cholera at Oxford in the Year 1854: with Considerations suggested by the Epidemic. By Henry Wentworth AcLand, M.D., F.R.S., F.R.G.S., etc., Physician to the Radeliffe Infirmary; Radcliffe Librariau; and Lee's Reader in Anatomy in the University of Oxford. pp. 171. London and Oxford: John Churchill and J.H. and J. Parker. 1856.

CAN anything good, in the shape of medical literature, come out of 0 xford? is a question to answer which, if it had been asked us but a short time ago, we should have been obliged to tax our memory and our charity somewhat heavily. Now, however, there would be no hesitation in answering in the affirmative, since Dr. AcLand has produced his Memoir on the Cholera in that city.

The work consists of three parts. Part I, treating of the History of the Epidemic, is divided into six chapters : 1. On the Course of the Disease in Oxford; 2. On the Cholera in the Neighbourhood of Oxford; 2 . Local Causes which may have influenced the Frogress of the Disease; 4 . Meteorology of the Epidemic (by Mr. Johnson); 5. Treatment of the Disease in Oxford; 6. The Conclusions. Part II treats of Arrangements made in Oxford during the Epidemic. Part III contains the Lesson of the Epidemic, in six chapters; viz., 1. Our Present Condition; 2. On some Habitations in Oxford, and their Ventilation; 3. The Drainage of Oxford; 4. On certain Points affecting Voluntary Institutions for giving Medical Aid ; 5. On certain Relations between Moral and Physical Improvement. 6. The Summary. Besides this, there are also an Appendix on some subjects of interest, and several maps and plates.

In the first Part we find related the following interesting circumstance in reference to the influence of water supply on cholera. It appears that there are two prisons in Oxfordthe City Gaol and the County Gaol. Neither in the cpidemic of 1832 nor in that of 1849 were there any cases of cholere in the City Caol ; in the County Gaol there were, in 1832,3 cases; in 1849,14 . In 1854, cholern appeared in the County Geol; and Dr. Acland was desired to report thereon to the magistrates. He found, accordingly, on September 29th, that there had been 5 cases of cholera, four of which had terminated fatally; and that there had also been 37 cases of diarrhoes among 95 prisoners in the course of a fortnight. At the same time, in the City Gaol there had been no cases of diarrhcea of any consequence, and none of cholera. The two prisons are not far apart; the County prison is admirably managed. What could be the cause of the difference?

"At a short distance from the gaol flows a branch of the river. It passed through a mill, the Castle Mill-is dammed up for the mill-head above the mill; and, when flowing through the mill, forms a brisk stream in the mill-tail, carrying with it wheterer impurities it obtained in the mill-head. When the mill is not at work, and the water is ponded up, the milltail becomes, as nearly all such spots do, a nearly stagnant pol. This year (1854) the river was unusually low; and, at the date of my inspection of the prison, this pool contained various garbage stationary on its surface and its bottom. Further, a drain from the prison flowed into the pool; within ten feet of the mouth of this running drain, the supply pipe from the prison sucked up the contents of the pool for the prison use. From this source the kitchen coppers were supplied, and from this water the soup and the gruel-important articles in the weekly diet-were prepared.

"No sooner was the attention of the governor of the prison drawn to this fact-barren though it might appear to be-than the pipes were cut off: and what followed? Whereas before this there had occurred twenty cases of choleraic diarrhoea, and five cases of cholera, of which four were fatal, after the following day, no more than three of choleraic diarrhœea, and one of cholera (none being fatal) were reported during the rest of the epidemic." (p. 5..)

Dr. Acland, however, only admits impure water as one of media through which cholera may be communicated. This, and other conclusions at which he has arrived at, are thus expressed :-

"Summary of the Principal Conclusions.-1. The history of both the city and the surrounding district unite in giving weight to the belief in the origin of cholera without communication with other cholers districts. 2. Both the city and the district give evidence of the occasional communication of the diseasefrom place to place, and from person to person. 3. They both lead us to the conviction that places, and attendants on cholera patients, may enjoy a perfect immunity from contagion. 4 From the survey of the city, we are inclined to believe that this immunity is less probable in proportion as less attention is paid to the destruction of the evacuations. 5. Contact with the evacuations is, therefore, exceedingly dangerous. 6 . The hypothesis which refers diarrhoea to the state of the atmosphere and cholera to the metamorphosis of diarrhœa evacuations by and in that atmosphere, derives support from these considerations. 7. The poison of the evacuations may be conveyed throngh the air, or by the agency of water. 8. Therefore poisoned water, though one means of spreading the disease, is not the only means. 9. For these reasuns, and from the facts observed, we may conclude, and do assert, that crowded dwellings and imperfect ventilation are dangerous in the highest. degree, during the prevalence of a cholera atmosphere, to those who are subjected to them; just as they are ruinous to health at other times. 10. We must, therefore, conclude that such dwellings, and such bad ventilation, are dangerous, not only to the persons exposed to them, but to the whole district or town which surrounds them. 11. A low scale of diet favours diarrhcea, and $\mathrm{a}$ better diet tends to check it. 12. Occupation exercised no marked influence in this district, and indeed persons in easy circumstances were more attacked proportionally than night-soil men, who work mostly in the open air. 13. The lower half of this city was most attacked; but the lives of those who reside in the upper and drained portions are unquestionably endangered by the condition of the lower and undrained parts. 14. Preparations for epidemic disease should not be left till the disease appears; there should, therefore, be wards in every town proper for receiving persons suffering from such disease. 15. Common prudence suggests that these wards should, in hospital towns of moderate size, be attached to, and be managed by the hospitul; that in smaller districts, as the law now stands, they should be under the control of the guardians; and 